\title{
Estandarización de la técnica de ELISA para diagnóstico de estrongiloidiosis
}

\author{
PEDRO HUAPAYA ${ }^{1}$, YRMA ESPINOZA $^{1,2}$, ALINA HUIZA $^{1,2}$, CARLOS SEVILLA $^{2}$ \\ ${ }^{1}$ Instituto de Medicina Tropical Daniel A. Carrión - UNMSM. \\ ${ }^{2}$ Departamento Académico de Microbiología Médica - Facultad de Medicina - UNMSM.
}

\begin{abstract}
RESUMEN
OBJETIVO: Estandarizar la técnica de ELISA para diagnóstico de la infección humana por el parásito Strongyloides stercoralis. MATERIAL Y MÉTODOS: Se preparó antígeno crudo usando larvas filariformes obtenidas de muestras de heces positivas cultivadas con carbón vegetal. Las larvas fueron trituradas mediante sonicación y lavadas por centrifugación para obtener extractos de proteínas para usarlos como antígeno. La concentración proteica final fue de $600 \mu \mathrm{g} / \mathrm{mL}$. Se probó varios tipos de placas de ELISA y se determinó las concentraciones de antígeno, sueros, conjugado y puntos de corte, para permitir la diferenciación de la infección. Los controles positivos fueron sueros de pacientes con síndrome de hiperinfección e infección intestinal, comprobados mediante exámenes parasitológicos de heces; y los controles negativos fueron sueros de personas provenientes de zonas no endémicas y con comprobación mediante exámenes parasitológicos de la ausencia del parásito. RESULTADOS: Los valores óptimos fueron $5 \mu \mathrm{g} / \mathrm{mL}$ para el antígeno, 1/64 para el suero, 1/1000 para el conjugado; los valores de densidad óptica para las muestras positivas fueron en promedio 1,2746 $(1,1065$ $1,4206, \mathrm{DS}=0,3284)$ y de las muestras negativas $0,4457(0,3324-0,5538, \mathrm{DS}=0,2230)$. Se examinó 20 muestras de suero de sujetos positivos y 100 de sujetos negativos, obteniéndose sensibilidad de $90 \%$ y especificidad de $88 \%$. CONCLUSIÓN: Los resultados muestran que esta técnica puede constituirse en una prueba de tamizaje de estrongiloidiosis en estudios de población.
\end{abstract}

Palabras clave: Strongyloides stercoralis; estrongiloidiosis; ELISA; serología; diagnóstico de laboratorio.

\section{ELISA TECHNIQUE STANDARDIZATION FOR STRONGYLOIDIASIS DIAGNOSIS SUMMARY}

OBJECTIVE: To standardize ELISA technique for human Strongyloides stercoralis infection diagnosis. MATERIAL AND METHODS: A crude antigen was prepared using filariform larvae obtained from positive stool samples cultured with charcoal. Harvested larvae were crushed by sonication and washed by centrifugation in order to obtain protein extracts to be used as antigen. Final protein concentration was $600 \mu \mathrm{g} / \mathrm{mL}$. Several kinds of ELISA plates were tested and antigen concentration, sera dilution, conjugate dilution and cut off were determined to identify infection. Sera from patients with both hyperinfection syndrome and intestinal infection demonstrated by parasitological examination were positive controls and sera from people living in non-endemic areas with no infection demonstrated by parasitological examination were negative controls. RESULTS: Best values were $5 \mu \mathrm{g} / \mathrm{mL}$ for antigen, 1/64 for sera, 1/1000 for conjugate; optical density values for positive samples were 1,2746 $(1,1065-1,4206, \mathrm{DS}=0,3284)$ and for negative samples $0,4457(0,3324-0,5538, \mathrm{DS}=0,2230)$. Twenty sera samples from positive subjects and one hundred from negative subjects were examined, obtaining $90 \%$ sensitivity and $88 \%$ specificity. CONCLUSION: The results show this technique could be useful as strongyloidiasis screening test in population studies.

Key words: Strongyloides stercoralis; strongyloidiasis; ELISA; serology; diagnosis laboratory.

Correspondencia:

Dr. Pedro Huapaya Herreros

Av. Oscar R. Benavides 5050 - Dpto. 204

Callao 02, Perú

E-mail: pehh@terramail.com.pe pedro_huapaya@latinmail.com 


\section{INTRODUCCIÓN}

La infección por parásitos de la especie Strongyloides stercoralis, conocida como estrongiloidiosis, es una parasitosis común en áreas de clima tropical. Este hecho ha sido descrito desde hace mucho tiempo por diversos autores, como Cornejo, quien ya desde 1948 reportó en nuestro país la existencia de esta parasitosis en poblaciones de la selva $\left({ }^{1-3}\right)$. Lo mismo ocurre con numerosos estudios que reportan a la región de la selva como la principal zona endémica $\left({ }^{4-10}\right)$.

Para el diagnóstico se requiere cumplir el examen de heces seriado (dos o tres muestras en días distintos) ya que la excreción larvaria no es continua y presenta variaciones entre los días de la semana y entre los diferentes momentos del día $\left({ }^{11-14}\right)$, llegando a requerirse la técnica de Baermann ( $\left.{ }^{15-19}\right)$ o en algunos casos repetir el examen de heces en múltiples muestras o realizar cultivos con varias técnicas ${ }^{20-22}$ ). Inclusive se ha llegado a recurrir metodología extremadamente especializada, como para estar disponible en todos los establecimientos de salud $\left({ }^{23}\right)$.

Desde 1977, se ha reconocido el valor potencial de la técnica de ELISA como método de diagnóstico de enfermedades parasitarias $\left({ }^{24}\right)$. A partir de 1981, Neva en los Institutos Nacionales de Salud (NIH) de los Estados Unidos de Norteamérica y otros autores en diversos países han demostrado la utilidad de la técnica ELISA en suero como método de diagnóstico indirecto de estrongiloidiosis, teniendo sensibilidad y especificidad promedios de $90 \%$, que la convierten en una alternativa para la detección eficaz de la infección $\left({ }^{25}\right.$ ) y para evaluar la evolución de la misma $\left({ }^{8}\right)$. Existen además otros trabajos realizados en zonas endémicas, donde la prueba de ELISA ha dado evidencia de ser útil como prueba de tamizaje de la infección ${ }^{(26-33}$ ).

Sin embargo, hasta la fecha no ha sido utilizada en nuestro país, donde podría ser una opción para el diagnóstico en los estudios epidemiológicos, sirviendo como prueba de tamizaje, detectando casos sospechosos en los cuales aplicar posteriormente la metodología de examen parasitológico habitual.

Por ello, se plantea el objetivo de estandarizar la técnica de ELISA en muestras de suero, para lograr el diagnóstico indirecto de estrongiloidiosis mediante el dosaje de anticuerpos específicos contra este parásito.

\section{MATERIALES Y MÉTODOS}

Se dividió el trabajo en dos etapas:

a. Preparación del antígeno: Se aisló larvas de $S$. stercoralis de muestras de heces positivas, procedentes de pacientes residentes en zonas endémicas (provincias de Chanchamayo y Satipo, departamento de Junín), así como de aquellos que concurrieron al Instituto de Medicina Tropical “Daniel A. Carrión”, por consultorio externo o por referencia de otros establecimientos de salud. Se examinó aproximadamente 50 pacientes, siendo seleccionados aquellos con mayor carga larvaria en heces, ya que el rendimiento en caso de infecciones leves no justifica el proceso posterior. Las larvas fueron cultivadas en carbón vegetal, obteniéndose larvas filariformes, que fueron recuperadas mediante el método de Baermann, para luego ser lavadas con buffer conservador de larvas (BCL) + gentamicina $(80 \mu \mathrm{g} / \mathrm{mL})$ (Tabla 1$)$, mediante centrifugación por tres veces. El sedimento se mezcló con lejía al 5\% para eliminar bacterias. Inmediatamente se repitió el lavado no menos de 5 veces, para eliminar los restos de lejía. Se mantuvo la temperatura del conjunto alrededor de $4^{\circ} \mathrm{C}$. Se contó el número de larvas presentes en el sedimento obtenido, se resuspendió el sedimento en BCL y se conservó en congelación $\left(-20^{\circ} \mathrm{C}\right)$ hasta tener cantidad suficiente de larvas (no menos de 1 millón de larvas). Se homogenizó los sedimentos y se les sometió a sonicación, hasta lograr la fragmentación de las larvas. Luego se realizó la extracción de proteínas, mediante agitación continua del conjunto durante toda la noche, a $4^{\circ} \mathrm{C}$ (aproximadamente 18 horas), y se centrifugó el material a 16500 rpm durante 30 minutos. Se retiró el sobrenadante, 
el sedimento fue resuspendido en BCL y se repitió todo el proceso durante tres días más, en que se tuvo cuatro extractos. Estos fueron colocados en membranas o tubos de diálisis, para ser sumergidos en no menos de 4 litros de PBS a $4^{\circ} \mathrm{C}$, el mismo que se cambió tres veces, con un intervalo no menor de 4 horas entre cada cambio. Finalmente, se concentró los cuatro extractos, utilizando el contacto con azúcar en polvo para extraer agua. Luego se procedió al dosaje de proteínas por el método de Lowry, obteniéndose una concentración de $600 \mathrm{ug} / \mathrm{mL}$; el antígeno obtenido se conservó por congelación $\left(-20^{\circ} \mathrm{C}\right)$ para su uso posterior.

Tabla 1. Composición del buffer conservador de larvas.

\begin{tabular}{ll}
\hline $\mathrm{Na}_{2} \mathrm{HPO}_{4}$ & $7,1 \mathrm{~g}$ \\
$\mathrm{KH}_{2} \mathrm{PO}_{4}$ & $3,0 \mathrm{~g}$ \\
$\mathrm{NaCl}$ & $4,1 \mathrm{~g}$ \\
Agua destilada & $100 \mathrm{~mL}$ \\
$\mathrm{pH}$ & 6,8 \\
\hline
\end{tabular}

b. Estandarización de la técnica: Para ello se utilizó como controles positivos las muestras de suero provenientes de 3 pacientes con diagnóstico de síndrome de hiperinfección, dos de ellos procedentes de la provincia de Chanchamayo, en Junín y otro de la provincia de La Convención en Cusco, junto con otros 17 de pacientes con estrongiloidiosis intestinal procedentes de Chanchamayo y Satipo (Junín), Iquitos (Loreto), Pucallpa (Ucayali) y Tingo Maria (Huánuco), quienes fueron captados tanto en los establecimientos de salud de sus localidades como en los consultorios externos del Instituto de Medicina Tropical Daniel A. Carrión de la UNMSM. Como controles negativos se utilizó sueros de 100 personas provenientes de zonas no endémicas (Huancayo, Cerro de Pasco, La Oroya, Lima), todos ellos con exámenes parasitológicos de heces negativos a Strongyloides. Con todos los sueros se realizó la titulación de la prueba, para obtener los valores óptimos de concentración del antígeno, dilución del suero, dilución del conjugado y del sustrato. Ello permitió obtener los puntos de corte para determinar el rango positivo y negativo de las lecturas de densidad óptica, utilizando varios tipos de placas de ELISA de distintos materiales, para determinar cual de ellos brinda mejores condiciones para la reacción.

El procedimiento de la prueba fue el siguiente:

- Se colocó $100 \mu \mathrm{L}$ del antígeno diluido en buffer carbonato en cada uno de los pozos de la placa.

- Se incubó toda una noche a $4^{\circ} \mathrm{C}$ (aproximadamente 18 horas), para lograr la sensibilización de la placa.

- Al día siguiente se lavó la placa no menos de cinco veces, utilizando $100 \mu \mathrm{L}$ de PBS con Tween 20 al $0,05 \%$, en cada uno de los pozos, se agitó ligeramente durante 3 minutos antes de cambiar el líquido.

- Se incubó la placa con una solución de PBSTween $0,05 \%$ y leche descremada al $5 \%$ durante una hora a $37^{\circ} \mathrm{C}$, para bloquear todos los espacios en los que el antígeno no se hubiera adherido.

- Se lavó la placa como ya ha sido descrito.

- Se añadió en cada pozo de la placa $100 \mu \mathrm{L}$ de cada uno de los sueros de trabajo, dejando una fila o columna conocidas que sirvieron como controles blanco.

- Se incubó la placa durante una hora a $37^{\circ} \mathrm{C}$, para permitir la reacción antígeno anticuerpo.

- Se lavó la placa como ya ha sido descrito.

- Se añadió en cada pozo de la placa $100 \mu \mathrm{L}$ del conjugado peroxidasa de carnero inmunoglobulina anti-IgG humana.

- Se incubó la placa durante una hora a $37^{\circ} \mathrm{C}$, para permitir la reacción del conjugado con el anticuerpo.

- Se lavó la placa como ya ha sido descrito.

- Se añadió en cada pozo de la placa $100 \mu \mathrm{L}$ del sustrato correspondiente: una tableta de orto-fenil-dietanolamina (OPD) disuelta en una mezcla de ácido cítrico y fosfato disódico a pH 5,0, a la que se añadió $20 \mathrm{uL}$ de peróxido de hidrógeno. 
- Se incubó la placa durante 20 a 30 minutos a temperatura ambiente y protegida de la luz, para permitir la reacción del conjugado con el sustrato, que origina coloración amarilla naranja.

- Se procedió a lectura de la densidad óptica en espectrofotómetro a $492 \mathrm{~nm}$.

Para la titulación de los componentes de la prueba se utilizó diluciones sucesivas del antígeno, del suero y del conjugado, determinando los mejores valores de densidad óptica que permitieran diferenciar las muestras positivas de las negativas. Así se trabajó concentraciones del antígeno de $80,40,20,10,5,2,5$ y $1,25 \mu \mathrm{g} /$ $\mathrm{mL}$; las diluciones del suero fueron $1 / 41 / 8,1 /$ $16,1 / 32,1 / 64,1 / 128,1 / 256$, mientras que el conjugado se diluyó sucesivamente entre $1 / 250$, $1 / 500,1 / 1000,1 / 2000$ y $1 / 4000$. Asimismo, se probó diversos tipos de placas para identificar aquella que brindara los mejores resultados.

Se identificó cada uno de los componentes de la prueba, cuya combinación permitió discriminar mejor los resultados.

Placas: Fabricadas con poliestireno transparente de marca Immulon 2 con fondo en "U".

Antígeno: La concentración óptima fue de $5 \mu \mathrm{g} /$ $\mathrm{mL}$, distribuido a razón de $100 \mathrm{uL}$ en cada pocillo.

Suero: La dilución óptima fue 1/64.

Conjugado: La dilución óptima fue 1/1000.

Puntos de corte: Los valores de densidad óptica para las muestras positivas fueron en promedio de $1,2746(1,1065-1,4206, \mathrm{DS}=0,3284)$ y de las muestras negativas fueron de 0,4457 $(0,3324-0,5538, \mathrm{DS}=0,2230)$.

Con todos estos componentes se realizó la prueba para examinar las muestras disponibles. De manera de catalogar positivos y negativos, se utilizó el siguiente criterio: cuando la lectura de densidad óptica se encontraba por encima del rango del promedio de los negativos más dos desviaciones estándar $(0,4457+2(0,2230)=$ $0,8917)$, la muestra fue considerada positiva.

\section{RESULTADOS}

Se obtuvo los resultados que se muestra en la Tabla 2.

Tabla 2. Resultados de ELISA.

\begin{tabular}{lccc}
\hline & $\begin{array}{c}\text { Ss } \\
\text { positivo }\end{array}$ & $\begin{array}{c}\text { Ss } \\
\text { negativo }\end{array}$ & $\begin{array}{c}\text { Total de } \\
\text { exámenes }\end{array}$ \\
\hline ELISA positiva & 18 & 12 & 30 \\
ELISA negativa & 2 & 88 & 90 \\
Total de pacientes & 20 & 100 & 120 \\
\hline
\end{tabular}

Con estos datos se obtiene valores de sensibilidad de $90 \%$ y especificidad de $88 \%$, los mismos que permiten afirmar que esta prueba puede tener utilidad para el tamizaje en población de la infección por Strongyloides stercoralis, siendo necesario evaluar un mayor número de muestras de individuos con diagnóstico positivo y negativo confirmados para poder tener una mejor idea de su verdadera eficacia e incluirla como instrumento para la investigación.

\section{DISCUSIÓN}

Los resultados del presente estudio corroboran los hallazgos de otros trabajos en distintos países que muestran la utilidad de la técnica de ELISA como método de diagnóstico de estrongiloidiosis $\left({ }^{25-27,29-33}\right)$. Así tenemos que el estudio de Lindo ( ${ }^{31}$ ) obtiene sensibilidad de $80 \%$ y especificidad de 93,5\%, mientras que Genta $\left({ }^{34}\right)$, obtiene sensibilidad de $97 \%$ y especificidad de $95 \%$, siendo éstos los valores más altos y bajos, respectivamente. Los demás fluctúan entre estas cifras, siendo todos de utilidad.

Cuando se evalúa la posibilidad de usar ELISA como método de diagnóstico en nuestro país, surge en primer lugar el factor económico, siempre importante cuando tratamos de desarrollar nueva tecnología, ya que puede resultar mucho más oneroso cuando se le compara con tecnología de diagnóstico más sencilla y 
menos costosa, como los exámenes de heces en sus diferentes técnicas. Sin embargo, varios autores han mostrado directa e indirectamente la posible falencia de estos métodos cuando se trata de obtener el diagnóstico correcto rápidamente, ya que esto no siempre es posible $\left({ }^{11-22}\right)$.

Por ello, planteamos que la técnica de ELISA puede ser utilizada como prueba de tamizaje, especialmente para estudios epidemiológicos en zonas de baja prevalencia. De esta manera se puede detectar rápidamente individuos sospechosos en quienes aplicar los exámenes de heces con la metodología convencional, que confirmen la presencia del parásito, tal como ya fue propuesto en estudios previos $\left({ }^{4,30}\right)$.

Se concluye que es necesario recolectar y procesar numerosas muestras de pacientes con estrongiloidiosis intestinal para poder obtener un número suficiente de larvas filariformes y así preparar el antígeno necesario. La preparación del antígeno es factible de realizar enteramente con la tecnología existente en nuestro país y en nuestra institución. El método de cultivo con carbón vegetal puede constituirse en un método de diagnóstico de estrongiloidiosis intestinal sencillo, eficaz y de costo bajo; en futuros estudios evaluaremos mejor su eficacia.

La técnica de ELISA tiene valores de sensibilidad y especificidad que la convierten en un examen potencialmente útil para el tamizaje de la infección. Los valores óptimos para aplicar la técnica de ELISA en el diagnóstico de estrongiloidiosis son $5 \mu \mathrm{g} / \mathrm{mL}$ como concentración del antígeno, 1/64 como dilución del suero y 1/1000 como dilución del conjugado. Es necesario examinar poblaciones con distintas prevalencias de la infección, para conocer mejor la eficacia de la prueba como método de tamizaje y diagnóstico.

\section{AGRADECIMIENTO}

A la Srta. Susana Jiménez de la sección de Parasitología del Instituto de Medicina Tropical “Daniel A. Carrión” por su valiosa colaboración en la ejecución de este trabajo.
Proyecto financiado por el Consejo Superior de Investigaciones - UNMSM. Código: 010101141.

\section{BIBLIOGRAFÍA}

1. Cornejo A, Gonzáles D, Dieguez J. Survey sobre parasitismo Intestinal en el personal técnico, administrativo y auxiliar de los Hospitales de Iquitos. Arch Per Patol Clín 1948; 2(1): 123-30.

2. Cornejo A. Incidencia de parasitismo intestinal por helmintos y protozoos en el Departamento de Madre de Dios. Anales Fac Med 1959; 52(4): 579-606.

3. Cornejo A, Vilchez M, Castillo A, Náquira C. Parasitismo por Strongyloides stercoralis en localidades de la carretera marginal de la selva Departamento de San Martín. Rev Cuerpo Méd Hosp Obrero Lima 1968; 7(3).

4. Genta R. Strongyloidiasis. En: Walls K, Schantz P, ed. Immunodiagnosis of Parasitic Diseases. Vol. 1, Helminthic Diseases. Florida,EE.UU:Academic Press,Inc.1986:183-99.

5. Huapaya $P$, Chávez V, Valverde $S$, Rose M. Prevalencia de Strongyloidiasis en lactantes y pre-escolares de la Provincia de Chanchamayo. Bol Per Parasitol 1995; 11: 32-4.

6. Kilpatrick M, Escamilla J, Barzotti A, Gutierrez W, Paulette E, Bonilla L. Parasitosis intestinales identificadas mediante examen de heces en tres grupos de población del Perú. Bol Of Sanit Panam 1986; 100(4).

7. Matos A. Prevalence of strongyloidiasis in ten municipalities of the Amazon State, Brazil, and its relation with soil and water physical chemical composition. Rev Soc Brasileira Med Trop 2000; 33(1): 107-8.

8. Neva F. Biology and immunology of human Strongyloidiasis. J Infect Dis 1986; 154(3): 397-406.

9. Tantaleán M, Atencia G. Nota sobre parasitismo intestinal diagnosticado en el IMT Daniel A. Carrión. Rev Per Med Trop UNMSM 1993; 7(2): 99-103.

10. Vildósola G. Estrongiloidiasis. Rev Gastroenterol Perú 1997; 17, Supl (1): S75-S91.

11. Dreyer G, Fernandes-Silva E, Alves S, Rocha A, Albuquerque R, Addiss D. Patterns of detection of Strongyloides stercoralis in stool specimens: Implications for diagnosis and clinical trials. J Clin Microbiol 1996; 34(10): 2569-71.

12. Girard de Kaminsky R. Evaluation of three methods for laboratory diagnosis of Strongyloides stercoralis infection. J Parasitol 1993; 79(2): 277-80.

13. Sato Y, Kobayashi J, Toma H, Shiroma Y. Efficacy of stool examination for detection of Strongyloides infection. Am J Trop Med Hyg 1995; 53(3): 248-50.

14. Uparanukraw P, Phongsri S, Morakote N. Fluctuations of larval excretion in Strongyloides stercoralis infection. Am J Trop Med Hyg 1999; 60(6): 967-73.

15. Ferrioli Filho F. Diagnóstico da Estrongiloidiase. Modificaçöes do método de Baermann-Morais. Rev Inst Med Trop Sao Paulo 1959; 1(2): 138-40. 
16. Ferrioli Filho F. Nova modificaçao do método de extraçao de Loos-Baermann para pesquisa de larvas de Strongyloides stercoralis nas fezes: Técnica do Pires. Rev Inst Med Trop Sao Paulo 1961; 3(1): 9-14.

17. Ferrioli Filho F. Condiçoes que influem na extraçao de larvas do Strongyloides stercoralis das fezes pelo método de Looss-Baermann modificado (Técnica do Pires). Rev Inst Med Trop Sao Paulo 1961; 3(2): 51-60.

18. Graeff C, Medeiros E, Zanini G, Brasil C, Cardozo B, Dalpiaz M, Bisol L. Inexpensive alternative material for the isolation of larvae with the Baermann method. Memorias Inst Oswaldo Cruz Rio Janeiro 1997; 92(3): 399-400.

19. Hernández F, Avendaño L. A simple modification of the Baermann method for diagnosis of Strongyloidiasis. Memorias Inst Oswaldo Cruz Rio Janeiro 2001; 96(6): 805-7.

20. Dos Santos J, Padilha O. Baixa sensibilidade do método de cultura de larvas (Harada-Mori) no diagnóstico da Estrongyloidiase. Rev Soc Brasileira Med Trop 1996; 29(1): 51-2.

21. Jongwutiwes S, Charoenkorn M, Sitthichareonchai $\mathbf{P}$, Akaraborvorn P, Putaporntip Ch. Increased sensitivity of routine laboratory detection of Strongyloides stercoralis and hookworm by agar-plate culture. Trans R Soc Trop Med Hyg 1999; 93: 398-400.

22. Jozefzoon L, Oostburg B. Detection of hookworm and hookworm-like larvae in human fecocultures in Suriname. Am J Trop Med Hyg 1994; 51(4): 501-5.

23. Ramachandran S, Thompson R, Gam A, Neva F. Recombinant cDNA clones for immunodiagnosis of Strongyloidiasis. J Infect Dis 1998; 177: 196-203.

24. Ruitenberg E, van Knapen F. The enzyme-linked immunosorbent assay and its application to parasitic infections. J Infect Dis 1977; 136, suppl: S267-S273.

25. Neva F, Gam A. Comparison of larval antigens in an enzyme-linked immunosorbent assay for Strongyloidiasis in humans. J Infect Dis 1981; 144(5): 427-32.
26. Carroll SM, Karthigasu Kt, Grove DI. Serodiagnosis of human Strongyloidiasis by an enzyme-linked immunosorbent assay. Trans R Soc Trop Med Hyg 1981; 75: 706-8.

27. Conway D, Atkins N, Lillywhite J, Bailey J, Robinson R. Lindo J, Bundy D, Bianco A. Immunodiagnosis of Strongyloides stercoralis infection: a method for increasing the specificity of the indirect ELISA. Trans R Soc Trop Med Hyg 1993; 87: 173-6.

28. Costa-Cruz J, Machado E, Campos D. Seroepidemiological study of human strongyloidiasis with blood samples collected on filter paper, in Abadía Dos Dourados (Minas Gerais, Brazil). Rev Inst Med Trop Sao Paulo 1998; 40(5): 329-31.

29. Gam A, Neva F, Krotoski W. Comparative sensitivity and specificity of ELISA and IHA for serodiagnosis of Strongyloidiasis with larval antigens. Am J Trop Med Hyg 1987; 37(1): 157-61.

30. Huapaya P, Suárez R, Espinoza Y. Utilidad de exámenes parasitológicos y serológicos como métodos de diagnóstico de estrongiloidosis humana. Ejercicio de metanálisis. Anales Fac Med 2002; 63(1): 7-12.

31. Lindo J, Conway D, Atkins N, Bianco A, Robinson R, Bundy D. Prospective evaluation of enzyme-linked immunosorbent assay and immunoblot methods for the diagnosis of endemic Strongyloides stercoralis infection. Am J Trop Med Hyg 1994; 51(2): 175-9.

32. Mangali A, Chaicumpa W, Nontasut $\mathbf{P}$, Chantavanij $\mathbf{P}$, Tapchaisri P, Viravan Ch. Enzyme-linked immunosorbent assay for diagnosis of human Strongyloidiasis. Southeast Asian J Trop Med Public Health 1991; 22(1): 88-92.

33. Sato Y, Takara M, Otsuru M. Detection of antibodies in strongyloidiasis by enzyme-linked immunosorbent assay (ELISA). Trans R Soc Trop Med Hyg 1985; 79: 51-5.

34. Genta R. Predictive value or an enzyme linked immunosorbent assay (ELISA) for the serodiagnosis of Strongyloidiasis. Am J Clin Pathol 1988; 89(3): 391-4. 